Goldschmidt 2021 Abstract

https://doi.org/10.7185/gold2021.6501

\section{Extending cluster derived LA-ICP-MS geochemical domains through optical microscopy image classification}

\section{MATTHEW J. CRACKNELL ${ }^{1}$, ROBERT SCOTT ${ }^{1}$ AND DANIEL FOULDS ${ }^{2}$}

${ }^{1}$ University of Tasmania

${ }^{2}$ Kirkland Lake Gold Inc.

Presenting Author: m.j.cracknell@utas.edu.au

Laser ablation inductively coupled plasma mass spectrometry (LA-ICP-MS) data can be collected across mineral grain surfaces as regularly spaced lines and processed to represent a grid. These LA-ICP-MS 'map' data provide spatially distributed quantitative estimates of multielement chemical concentrations. This information can be used to interpret microscale compositional and textural domains. Clustering methods provide an alternative to manually analysing individual LA-ICP-MS maps. The resulting geochemical domains support interpretation of growth zones and core-rim relationships that would be difficult using individual elements (Ahmed et al., 2020).

Prior to LA-ICP-MS analysis, optical a microscopic imagery is typically acquired. Microscopy imagery is cheaper and easier to collect than LA-ICP-MS data and is often captured over larger regions and across more samples. These images do not generally contain the rich multielement information within LA-ICP-MS maps. However, chemical etching of polished grains can enhance certain compositional and textural features. Specifically for pyrite, etching polished surfaces with sodium hypochlorite solution $(\mathrm{NaOCl})$ promotes rapid tarnishing. Variations in concentrations of common trace elements in pyrite, such as arsenic, influence tarnish intensity. Given that substitution of gold into the pyrite crystal lattice is facilitated by high arsenic concentrations, Au-As rich growth zones in pyrite should be resolvable in etched pyrite microscopy images. Where LA-ICPMS maps and microscopy images are spatially coincident, an opportunity exists to use the LA-ICP-MS derived geochemical domains to classify the images of etched pyrite grains and thus extend geochemical insight.

In this research we present a case study whereby clustering of As-rich pyrite LA-ICP-MS maps generates geochemical domains representing the paragenetic history of the Fosterville orogenic gold deposit, Australia. LA-ICP-MS domains (Figure 1a) are aligned with an optical microscopy image of $\mathrm{NaOCl}$ etched pyrite (Figure 1b) and coincident regions are used to train an image classifier. The classifier predicts the spatial distribution of geochemical domains, both outside the LA-ICP-MS map area and in other microscopy images (Figure 1c).

\section{Reference}

Ahmed, A.D., Hood, S.B., Cooke, D.R., Belousov, I., 2020. Unsupervised clustering of LA-ICP-MS raster map data for geological interpretation: A case study using epidote from the Yerington district, Nevada. Applied Computing and Geosciences 8,100036 .
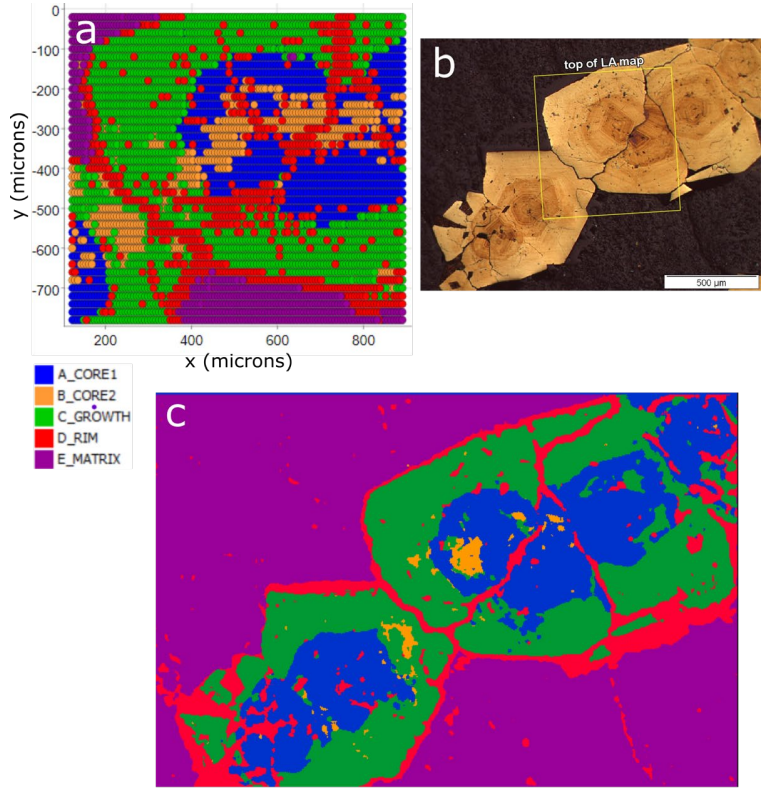

Figure 1. Fosterville pyrite: (a) clustering derived LA-ICP-MS geochemical domains; (b) optical microscopy image of $\mathrm{NaOCl}$ etched pyrite (yellow outline indicates LA-ICP-MS coincident region); and (c) optical microscopy image in b classified as geochmical domians. 